\title{
Assessment of Adherence to International Standards for Tuberculosis Care among Private Practitioners of Delhi
}

\author{
Rashmi Agarwalla, Asna Jamal, Ekta Gupta, Rambha Pathak, Meely Panda, Faheem Ahmed \\ Department of Community Medicine, Hamdard Institute of Medical Sciences and Research, New Delhi, India
}

\section{Abstract}

Context: Tuberculosis (TB) is among the top ten causes of mortality, and to control this growing burden of disease, it is imperative that all TB patients receive the same quality of care, based on the best evidence available. The best practices for TB as enshrined in the International Standards of TB Care (ISTC) if adhered to can expedite the efforts to control TB. Aims: The aim of the study was to evaluate the current practices for diagnosis and treatment of TB among the private medical practitioners against benchmark practices in ISTC and to assess the factors associated with adherence to ISTC. Subjects and Methods: A cross-sectional study was conducted among fifty private practitioners (PPs) of Delhi over a period of 3 months. Data collection was done using a structured pro forma, and interviews were conducted privately in the PPs' office. The key outcome variable was the proportion of practitioners adhering to the ISTC standards of diagnosis (standards: 1-6) and treatment (standards: 7-13). Results: Among fifty practitioners, $42 \%$ were found to be adherent, while $58 \%$ were found to be non-adherent. Significant association was found between gender and any form of training/sensitization received in the Revised National Tuberculosis Control Program (RNTCP) $(P<0.05)$. Conclusion: As the adherence to the ISTC care among the PPs was poor, there is a need to train and give incentives to participating PPs in timely and regulated way. PPs play a key role in diagnosing and treating TB patients, and hence, timely training and orientation in RNTCP and standard treatment for TB care are essential and should be key priority areas.

Keywords: Adherence, International Standards of Tuberculosis Care standards, private practitioners, tuberculosis

\section{INTRODUCTION}

Tuberculosis (TB) is among the top ten causes of mortality worldwide. In 2017, the global incidence of TB was estimated to be 10 million. ${ }^{[1]}$ Since the past 5 years, TB has surpassed HIV/AIDS in becoming the leading cause of death from a single infectious agent. ${ }^{[2]}$ India accounts for one-fourth of the global TB burden. ${ }^{[1,3]}$ In 2017, the number of incident cases of TB was 211 per 100,000 , and the number of deaths due to TB was $435,000 .^{[3,4]}$

Revised National Tuberculosis Control Program (RNTCP) is one of the largest national programs in India which provides free health-care services for TB patients. In spite of this government program, almost $85 \%$ of the patients having symptoms related to TB in urban India visit private practitioners (PPs) for their health-care needs, ${ }^{[5,6]}$ and roughly, half of them $(50 \%)$ ultimately receive treatment for $\mathrm{TB}$ outside the program. ${ }^{[7,8]}$

To control this growing burden of disease, it is imperative that all TB patients receive the same quality of care, based

\begin{tabular}{|l|l|}
\hline \multicolumn{2}{|c|}{ Access this article online } \\
\hline Quick Response Code: & Website: \\
\hline & www.ijrconline.org \\
\hline & \\
\hline
\end{tabular}

on the best evidence available. The best practices for TB are enshrined in the International Standards of TB Care (ISTC). These standards were first published in 2006 followed by the second edition in 2009, and the third edition was released recently on World TB day 2014. ${ }^{\left[{ }^{[9]}\right.}$ Based on the ISTC, several countries have drafted country-specific adaptations, including the Standards for TB Care in India. ${ }^{[10]}$

In spite of this, there is rampant usage of inappropriate diagnostic procedures and treatment practices for TB among the PPs in India. Furthermore, adherence to the ISTC continues to be low among them, ${ }^{[7,8,11-13]}$ thereby causing delays in the diagnosis of TB and continuing disease transmission and development of resistance to existing drugs. ${ }^{[8,12,14]}$ The study

Address for correspondence: Dr. Ekta Gupta G-27/3 Rajouri Garden, New Delhi - 110 027, India. E-mail: ekta273@gmail.com

This is an open access journal, and articles are distributed under the terms of the Creative Commons Attribution-NonCommercial-ShareAlike 4.0 License, which allows others to remix, tweak, and build upon the work non-commercially, as long as appropriate credit is given and the new creations are licensed under the identical terms.

For reprints contact: reprints@medknow.com

How to cite this article: Agarwalla R, Jamal A, Gupta E, Pathak R,
Panda M, Ahmed F. Assessment of adherence to international standards
for tuberculosis care among private practitioners of Delhi. Indian J Respir
$\begin{array}{ll}\text { Care 2020;9:58-61. } & \\ \text { Received: } 21-05-2019 & \text { Revised: } 27-06-2019 \\ \text { Accepted: } 19-09-2019 & \text { Published: } 08-01-2020\end{array}$


was thereby planned to evaluate the current practices for diagnosis and treatment of TB among the private medical practitioners against benchmark practices articulated in the ISTC and to assess the factors associated with adherence with ISTC.

\section{Subjects and Methods}

This cross-sectional study was conducted among the PPs of Delhi. The sample size for the present study consisted of 50 PPs practicing allopathic medicine. PPs observing $>10$ patients per day and those who gave consent were included for the study, while those who refuse to participate were excluded. The data collection was carried out over 2 months (the summer vacation time was utilized for data collection).

After obtaining consent, the interview was conducted privately in the PPs' office. The diagnostic and therapeutic practices for TB were assessed, and the key outcome variable was the proportion of practitioners adhering to the ISTC standards of diagnosis (standards: 1-6) and treatment (standards: 7-13). ${ }^{[10]}$

The questionnaire consisted of both vignettes and open and closed-ended questions. Vignette questions were provided to the practitioners in the form of case narration, and their response was compared to the expected standard response. If it was found to be the same, it was recorded as correct, and if the answer deviated from the principles in the standards, it was recorded as incorrect. Questions for the assessment of diagnostic practices which were part of standards 3-5 and assessment of treatment practices which were part of standards 11 and 12 were vignette based.

\section{Operational definition}

\section{Adherent to the International Standards of Tuberculosis}

Care

The criteria for classifying PPs into adherent and nonadherent to ISTC standards were whether they followed three selected and core ISTC standards (use of cough for 2 weeks for identifying pulmonary TB suspects; sputum microscopy for diagnosing pulmonary TB; and use of the 6-9-month fixed-dose combination regimen for treating TB). Any practitioner who was adhering to all the three ISTC standards was labeled as "adherent with ISTC," while others were classified as "non-adherent."[12]

\section{Method of data analysis}

Data entry was done in SPSS version 22 (IBM Corp., Armonk, NY, USA). Frequency and percentage distribution were used to analyze demographic data. Proportions were compared using frequency distributions and Chi-square test or Fisher's exact test. The value of $P$ was calculated at $95 \%$ confidence intervals and was considered as statistically significant if $\leq 0.05$.

\section{Ethical consideration and consent}

Informed consent was obtained from all the participants, and the confidentiality and privacy of the participants was maintained. Ethical clearance was obtained from the institute before beginning the study.

\section{RESULTS}

As observed in the study, $60 \%$ were general physicians. About

\begin{tabular}{|c|c|c|}
\hline Diagnostic practices & $\begin{array}{l}\text { Number of } \\
\text { respondents }\end{array}$ & $\begin{array}{c}\text { Number } \\
\text { adhering to ISTC } \\
\text { standards, } n(\%)\end{array}$ \\
\hline $\begin{array}{l}\text { Standard 1: Cough of } 2 \text { weeks to } \\
\text { suspect TB }\end{array}$ & 50 & $43(86)$ \\
\hline $\begin{array}{l}\text { Standard 2: Two sputum smear } \\
\text { sample examination for the } \\
\text { diagnosis of pulmonary TB }\end{array}$ & 50 & $38(76)$ \\
\hline $\begin{array}{l}\text { Standard 3: Extrapulmonary TB } \\
\text { diagnosis based on appropriate } \\
\text { investigations }\end{array}$ & 50 & $27(54)$ \\
\hline $\begin{array}{l}\text { Standard 4: Sputum } \\
\text { microbiological examination in } \\
\text { those with radiological findings } \\
\text { suggestive of TB }\end{array}$ & 50 & $18(36)$ \\
\hline $\begin{array}{l}\text { Standard 5a: Diagnose sputum } \\
\text { smear-negative pulmonary TB } \\
\text { based on both sputum microscopy } \\
\text { and X-ray }\end{array}$ & 50 & $22(44)$ \\
\hline $\begin{array}{l}\text { Standard } 5 \mathrm{~b} \text { : Use of the right trial } \\
\text { antibiotic }\end{array}$ & 50 & $35(70)$ \\
\hline $\begin{array}{l}\text { Standard 6: Diagnose pediatric } \\
\text { TB based on at least three of five } \\
\text { recommended approaches }\end{array}$ & 22 & $10(45)$ \\
\hline
\end{tabular}

TB: Tuberculosis, ISTC: International Standards of TB Care

Table 2: Private practitioners adhering to International Standards of Tuberculosis Care treatment practices

\begin{tabular}{lcc}
\hline Treatment practices & $\begin{array}{c}\text { Respondents } \\
(\boldsymbol{n})\end{array}$ & $\begin{array}{c}\text { Number } \\
\text { adhering to ISTC } \\
\text { standards, } \boldsymbol{n} \text { (\%) }\end{array}$ \\
\hline $\begin{array}{l}\text { Standard 7: Adopt methods to ensure } \\
\text { adherence to treatment }\end{array}$ & 50 & $29(58)$ \\
$\begin{array}{l}\text { Standard 8: Prescribe standard TB } \\
\text { treatment regimen }\end{array}$ & 50 & $34(42)$ \\
$\begin{array}{l}\text { Standard 9: Practice DOT or foster } \\
\text { adherence with treatment supporter or } \\
\text { other enablers }\end{array}$ & 50 & 0 \\
$\begin{array}{l}\text { Standard 10: Follow-up cases with } \\
\text { sputum microscopy }\end{array}$ & 50 & $32(64)$ \\
$\begin{array}{l}\text { Standard 11: Prescribe culture } \\
\text { and drug susceptibility testing for } \\
\text { previously treated TB cases }\end{array}$ & 50 & $24(48)$ \\
$\begin{array}{l}\text { Standard 12: For diagnosed DR TB, } \\
\text { prescribe standardized regimen, } \\
\text { or individualized TB treatment } \\
\text { regimen based on availability of drug } \\
\text { susceptibility testing }\end{array}$ & 50 & $11(22)$ \\
$\begin{array}{l}\text { Standard 13: Maintain the patient } \\
\text { clinical record }\end{array}$ & & \\
\hline
\end{tabular}

TB: Tuberculosis, ISTC: International Standards of TB Care, DOT: Directly observed treatment, DR: Drug resistant 
Agarwalla, et al.: Adherence to international standards for tuberculosis

\begin{tabular}{|c|c|c|c|}
\hline Characteristic & \multicolumn{3}{|c|}{ Adherent to ISTC (standard 1+2+8), $n(\%)$} \\
\hline Adherent & \multicolumn{3}{|c|}{$21(42)$} \\
\hline Nonadherent & \multicolumn{3}{|c|}{$29(58)$} \\
\hline \multicolumn{4}{|c|}{ ISTC: International Standards of Tuberculosis Care } \\
\hline \multicolumn{4}{|c|}{$\begin{array}{l}\text { Table 4: Characteristics of private practitioners in relation } \\
\text { to compliance with three selected core International } \\
\text { Standards of Tuberculosis Care standards }\end{array}$} \\
\hline \multirow[t]{2}{*}{ Characteristic } & \multicolumn{2}{|c|}{$\begin{array}{l}\text { Number (percentage } \\
\text { column-wise) }\end{array}$} & \multirow[t]{2}{*}{$P(\mathrm{Cl}), \mathrm{OR}$} \\
\hline & $\begin{array}{l}\text { Adherent to } \\
\text { ISTC }(n=21)\end{array}$ & $\begin{array}{l}\text { Nonadherent } \\
\qquad(n=29)\end{array}$ & \\
\hline \multicolumn{4}{|l|}{ Gender } \\
\hline Male & $18(85)$ & $16(55)$ & 0.032 \\
\hline Female & $3(15)$ & $13(45)$ & $\begin{array}{c}(1.17-20.26), \\
4.875\end{array}$ \\
\hline \multicolumn{4}{|c|}{$\begin{array}{l}\text { RNTCP } \\
\text { training/sensitization }\end{array}$} \\
\hline Yes & $10(48)$ & $5(17)$ & 0.0299 \\
\hline No & $11(52)$ & $24(73)$ & $\begin{array}{c}(1.20-15.84), \\
4.364\end{array}$ \\
\hline \multicolumn{4}{|l|}{ Specialty } \\
\hline MBBS & $13(62)$ & $17(59)$ & 1.000 \\
\hline Specialist & $8(38)$ & $12(41)$ & $\begin{array}{c}(0.363-3.62), \\
1.147\end{array}$ \\
\hline \multicolumn{4}{|l|}{ Years of practice } \\
\hline$<20$ & $14(67)$ & $15(51)$ & 0.387 \\
\hline$>20$ & $7(33)$ & $14(49)$ & $\begin{array}{c}(0.58-5.97), \\
1.867\end{array}$ \\
\hline
\end{tabular}

ISTC: International Standards of Tuberculosis Care, RNTCP: Revised National Tuberculosis Control Program, OR: Odds ratio, CI: Confidence interval

$16 \%$ were pediatrician, $6 \%$ were pulmonologists, $4 \%$ were surgeons, and $14 \%$ were gynecologists. In the study, $68 \%$ were male and $32 \%$ were female. Among the practitioners, $18 \%$ had $<10$ years of experience, $40 \%$ had $10-20$ years of experience, $24 \%$ had $21-30$ years of experience, and $18 \%$ had 31-40 years of experience.

Among the practitioners, $20 \%$ were observing $<20$ patients per day, $32 \%$ were observing $20-30$ patients per day, and $48 \%$ were observing $>30$ patients per day. More than half of the practitioners $(54 \%)$ were seeing less than $5 \mathrm{~TB}$ patients per month while one-fourth of practitioners $(24 \%)$ were seeing 5-10 TB patients per month and $22 \%$ practitioners were seeing more than $10 \mathrm{~TB}$ patients per month.

Tables 1 and 2 show PPs adhering to ISTC for the diagnosis and treatment. It was observed that $86 \%$ were adhering to standard $1,76 \%$ to standard $2,54 \%$ to standard 3, 36\% to standard $4,44 \%$ to standard 5 , and $45 \%$ to standard 6 . About $58 \%$ were adhering to standard $7,42 \%$ to standard $8,64 \%$ to standard $10,48 \%$ to standard $11,22 \%$ to standard 12 , and $76 \%$ to standard 13 . None of them were adhering to standard 9. On analyzing the adherence as per definition,
$42 \%$ were found to be adherent, while $58 \%$ were found to be non-adherent [Table 3].

Table 4 shows an association between adherence to ISTC standards and various independent variables. A significant association was found between gender and any form of training/sensitization received in $\mathrm{RNTCP}(P<0.05)$.

\section{Discussion}

The study information is based on the information collected from fifty doctors of Delhi. Based on the data collected with the help of a self-prepared questionnaire, following findings have been observed. It was found that maximum number of doctors, i.e. $60 \%$, were general physicians and $30 \%$ were specialists. As per gender and age distribution, $68 \%$ were male, while $32 \%$ were female. Majority were $<55$ years of age. A study by Achanta et al. in Andhra Pradesh also has $70 \%$ respondents as males and majority below 60 years of age. ${ }^{[12]}$

As per the study, $18 \%$ had $<10$ years of experience, while $82 \%$ had $>10$ years of experience. The respondents in a study in Kerala had also majority of respondents having $>10$ years of experience. ${ }^{[13,15]}$ As reported in the study, $48 \%$ of PP were observing more than thirty patients per day and $22 \%$ were observing more than ten TB patients in a month.

When asked whether they received any form of training or sensitization in RNTCP, 30\% said that they had gone for some form of training, while $70 \%$ did not have any training. While assessing the treatment and diagnostic practices followed by PPs as per the ISTC, it was observed that $86 \%$ were adhering to standard $1,76 \%$ to standard $2,54 \%$ to standard 3, 36\% to standard $4,44 \%$ to standard 5 , and $45 \%$ to standard 6 . While assessing the adherence of respondents to treatment practices based on the ISTC, $58 \%$ were found to be adherent to standard $7,42 \%$ to standard $8,64 \%$ to standard $10,48 \%$ to standard $11,22 \%$ to standard 12 , and $76 \%$ to standard 13 . None of them were adherent to standard 9 . Only $42 \%$ of practitioners were adherent to ISTC standards $(1+2+8)$, while $58 \%$ were found to be nonadherent. A study done by Achanta et al. in Andhra Pradesh found that only 28 (14\%) PPs were compliant with these three selected core ISTC standards. ${ }^{[12]}$

Table 4 shows the relationship between the characteristics of practitioners and compliance with each of the standards and all three ISTC standards together. Male practitioners and those who were sensitized to RNTCP guidelines showed a higher level of compliance with all three standards as compared to females and those who were not sensitized. Similar findings were also found by Achanta et al..$^{[12]}$

\section{Limitations}

Only those PPs who were reporting in Nikshay gave consent to participate in the study, and hence, it is prone to selection bias. The data collection on diagnostic and treatment practices for TB was self-reported by the PPs and may differ from their actual practice. Furthermore, there could be a response bias. 


\section{Conclusion}

As per the study, the adherence to ISTC care among the PPs was poor. Hence, there is a need to train and give incentives to participating PPs in a timely and regulated way. As TB elimination remains as a big challenge and PPs play in a key role in diagnosing and treating them, timely training and orientation in RNTCP and standard treatment for TB care are essential and should be key priority areas.

\section{Financial support and sponsorship}

This study was financially supported by ICMR, New Delhi.

\section{Conflicts of interest}

There are no conflicts of interest.

\section{RefERENCES}

1. World Health Organization. Global Tuberculosis Report. World Health Organization; 2018. Available from: http://www.who.int/tb/ publications/global_report/en/. [Last accessed on 2018 Sep 19].

2. World Health Organization. A Global Action Framework for TB Research in Support of the Third Pillar of WHO's End TB Strategy. The WHO Document Production Services. Geneva: World Health Organization; 2015. Available from: http://www.who.int/tb/publications/strategy/ en/. [Last accessed on 2018 Sep 19].

3. Ministry of Health and Family Welfare. Central TB Division. RNTCP Annual Status Report - 2018. India: Ministry of Health and Family Welfare; 2018. p. 176. Available from: https://tbcindia.gov.in/showfile. php?lid=3314. [Last accessed on 2018 Sep 19].

4. Regional Office for South-East Asia, World Health Organization!" Bending the Curve - Ending TB: Annual Report 2017. India: WHO Regional Office for South-East Asia; 2017. p. 1-76. Available from: http://www.who.int/iris/handle/10665/254762. Last accessed on 2018 Sep 19].
5. Sreeramareddy CT, Qin ZZ, Satyanarayana S, Subbaraman R, Pai M. Delays in diagnosis and treatment of pulmonary tuberculosis in India: A systematic review. Int J Tuberc Lung Dis 2014;18:255-66.

6. Bronner Murrison L, Ananthakrishnan R, Swaminathan A, Auguesteen S, Krishnan N, Pai M, et al. How do patients access the private sector in Chennai, India? An evaluation of delays in tuberculosis diagnosis. Int J Tuberc Lung Dis 2016;20:544-51.

7. Udwadia ZF, Pinto LM, Uplekar MW. Tuberculosis management by private practitioners in Mumbai, India: Has anything changed in two decades? PLoS One 2010;5:e12023.

8. Satyanarayana S, Subbaraman R, Shete P, Gore G, Das J, Cattamanchi A, et al. Quality of tuberculosis care in India: A systematic review. Int J Tuberc Lung Dis 2015;19:751-63.

9. TB CARE I. International Standards for Tuberculosis Care. $3^{\text {rd }}$ ed. TB CARE I; The Hague: 2014. Available from: http://www.who.int/tb/ publications/ISTC_3rdEd.pdf. [Last accessed on 2018 Oct 07].

10. World Health Organization, Central TB Division, Ministry of Health and Family Welfare, Government of India. Standards for TB Care in India. India: World Health Organization, Central TB Division, Ministry of Health and Family Welfare, Government of India; 2014. Available from: http://tbevidence.org/wpcontent/http://tbevidence.org/wpcontent/ uploads/2014/04/STCI-2014.pdf. [Last accessed on 2018 Oct 07].

11. Uplekar M, Juvekar S, Morankar S, Rangan S, Nunn P. Tuberculosis patients and practitioners in private clinics in India. Int J Tuberc Lung Dis 1998:2:324-9.

12. Achanta S, Jaju J, Kumar AM, Nagaraja SB, Shamrao SR, Bandi SK, et al. Tuberculosis management practices by private practitioners in Andhra Pradesh, India. PLoS One 2013;8:e71119.

13. Bharaswadkar S, Kanchar A, Thakur N, Shah S, Patnaik B, Click ES, et al. Tuberculosis Management Practices of Private Practitioners in Pune Municipal Corporation, India. PLoS ONE. 2014;9:e97993.

14. Pai M, Das J. Management of tuberculosis in India: time for a deeper dive into quality. The National Medical Journal of India. 2013;26:65-68.

15. Philip S, Isaakidis $P$, Sagili KD, Meharunnisa A, Mrithyunjayan S, Kumar AM. They Know, They Agree, but They Don't Do- The Paradox of Tuberculosis Case Notification by Private Practitioners in Alappuzha District, Kerala, India. PLoS ONE 2015;10:e0123286. 